\title{
Reconstruction, validation, and standardization of the extended objective Measure of Ego Identity Status-2 (EOM-EIS-2) and preparing its short form in Iranian society
}

\author{
Mohammad Solgi ${ }^{1}$, Bahram Saleh Sedgh Pour ${ }^{2}$ \\ 1-Assistant Professor, Department of Psychology, Jahad Daneshgahi - Academic Center for Education, Culture \& \\ Research (ACECR), Tehran, Iran (Corresponding Author). $\quad$ E-mail: solgy204@ yahoo.com \\ 2- Associate Professor, Department of Psychology, Shahid Rajaee Teacher Training University, Tehran, Iran.
}

Received: 30/10/2020

Accepted: 19/01/2021

\begin{abstract}
Introduction: An appropriate tool for measuring personal identity has already been developed by Adams et al but, it is not yet clear to what extent this tool and its items are in line with the requirements of Iranian culture.

Aim: This study aimed to reconstruct, validation and standardization of the extended objective measure of ego Identity Status-2 (EOM-EIS-2) and preparing its short form in Iranian society.

Method: The study population consisted of 524 students of Tehran state-run universities and was selected by cluster random sampling method. Item analysis such as item discrimination and loop, construct validation (factor analysis) and reliability analysis (Cronbach Alpha) were utilized.

Results: During the factor analysis, 8 factors were identified, 6 of which were consistent with the concepts of Identity status. Reliability assessment by computing Cronbach's alpha coefficient for each of the 4 Identity statuses and for the instrument were above 0.7 and 0.886 respectively. During the validation process, 15 questions were removed due to the reduction of validity evidence. Finally, taking into 6 omitted questions during the reliability analysis process (due to the reduction of reliability evidence); the number of omitted questions reached 21 and a shortened Iranian questionnaire with 43 items was prepared and presented.

Conclusion: It can be concluded Persian version of Measure of Ego Identity Status-2 (EOMEIS-2) in Iranian culture possesses an appropriate validity and reliability. Also, the factors obtained from the factor analysis and the short form presented can adequately measure the Identity statuses.
\end{abstract}

Keywords: Personal identity, Identity status, Standardization, Short-form, Iranian version

How to cite this article : Solgi M, Saleh Sedgh Pour B. Reconstruction, validation, and standardization of the extended objective Measure of Ego Identity Status-2 (EOM-EIS-2) and preparing its short form in Iranian society. Shenakht Journal of Psychology and Psychiatry. 2021; 7 (6): 140-151 .URL: http://shenakht.muk.ac.ir/article-1-1144-en.pdf

Copyright $\odot 2018$ the Author (s). Published by Kurdistan University of Medical Sciences. This is an open access article distributed under the terms of the Creative Commons Attribution-Non Commercial License 4.0 (CCBY-NC), where it is permissible to download, share, remix, transform, and buildup the work provided it is properly cited. The work cannot be used commercially without permission from the journal. 


\title{
بازساخت، رواسازى، هاياسازى و هنجاريابى ير سشنامه كسترش يافته سنجش عينى هويت من و تهيه فرم كوتاه آن در جامعه ايرانى (EOM- EIS-2)
}

\author{
محمد سلكى'، بهرام صالح صدقيور' \\ ا.استاديار، كروه روانشناسى، جهاد دانشكاهى، تهران، ايران (مولف مسئول). ايميل: Solgy2042@yahoo.com

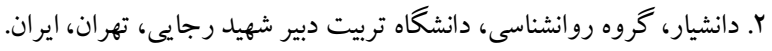

مقدمه: براى سنجش هويت فردى قبلاً ابزارى مناسب توسط آدامز و همكاران تهيه شده است اما هنوز مشخص نيست كه اين ابزار و

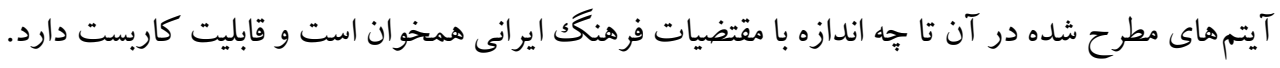
هدف: مطالعه حاضر با هدف بازساخت، رواسازى، باياسازى و هنجاريابى آزمون هويت فردى مشهور به برسشنامه گترش يافته

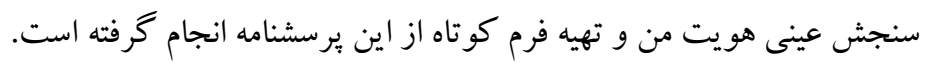

روش: شر كت كند گان اين يُزوهش

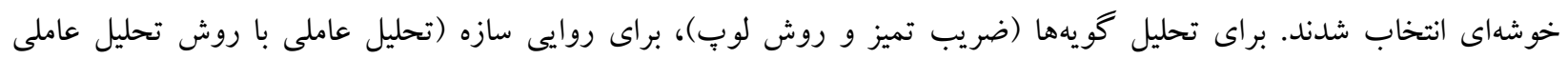
اكتشافى) و براى اعتبار نيز (محاسبه ضريب آلفاى كرونباخ) مورد استفاده قرار خرفت.

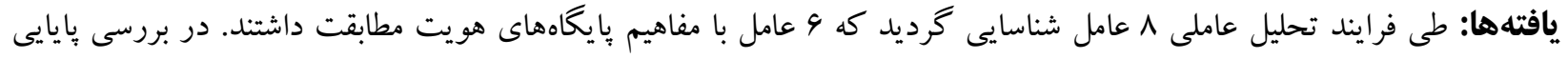

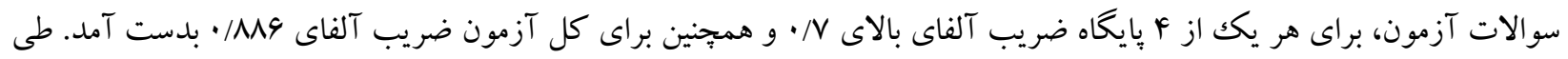

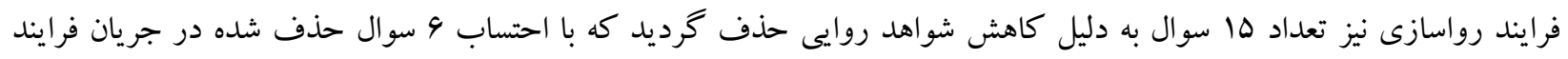

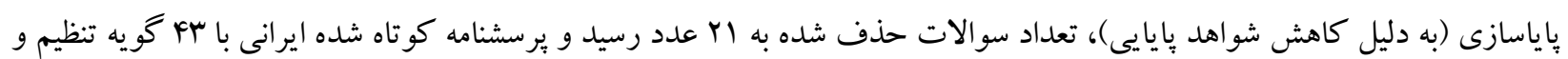
ارائه خرديد.

نتيجه كيرى: در مجموع مى توان نتيجه گرفت كه اين برسشنامه از بايايى و روايى مناسبى در فرهنگ ايرانى برخوردار است و عوامل

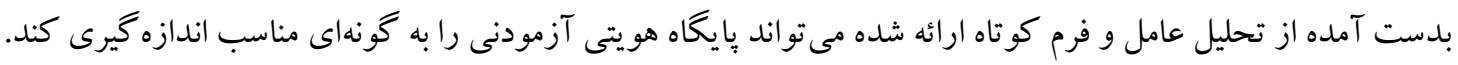
كليدوازهها: هويت فردى، بايڤاه هويت، هنجارسازى، فرم كو تاه، نسخه ايرانى 
(دان، مكك آدامز و كاكس4" ، (Y.1). مىتوان كفت كه مقدمه وازه هويت داراى دو معناى اصلى است: معناى اول آن بيانكر مفهوم تشابه مطلق است و معناى دوم آن به معناى

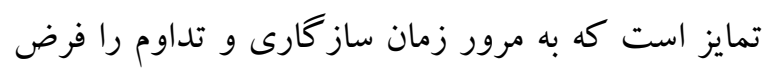
مى كيرد. بنابر اين مفهوم هويت- به معناى اصطلاحى آن - ميان اشيا و افراد دو نسبت محتمل را برقرار مى سازد؛ از يكك طرف شباهت و از طرف ديخر تفاوت (تويلويسكا و

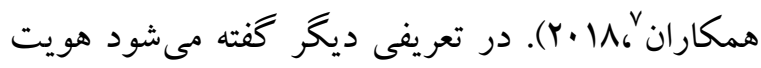
شناختن و شناساندن است و اين دو وجه دارد: يكى شناخت خود در ارتباط با جيزى و ديخرى شناساندن خود براساس آن جيز به ديخران. لذا تعريفى كه فرد از خود و و اولين آكاهى كه از خود بيدا مى كند هويت مىنامند. بنابر اين هويت هم شناختن خويش است، هم معرفى خود به ديخران (احمدى، برش|). در اين ميان هويت فردى تعريف فرد از خود با تأكيد بر تفاوتش از ديخران است. هويت فردى علىرغم ثبات نسبى داراى يويايى است و

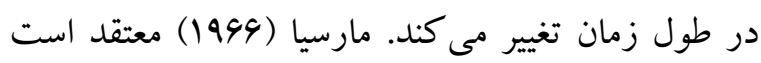
هويت مىتواند به عنوان ساختار خود در نظر كرفته شود؛ كه عبارت است از يكك سازمان بويا، خود ساخته و درونى از كشانندها، توانايىها، باورها و تاريخجه فردى. تحول اين ساختار زمانى است كه افراد نسبت به يخانكى شان و شباهتشان با ديخران و نقاط ضعف و قوت خود در روشهايى كه در جهان اتخاذ مى كنند آكاهتر باشند و تكيه بيشترى بر منافع بيرونى براى ارزشيابى خود

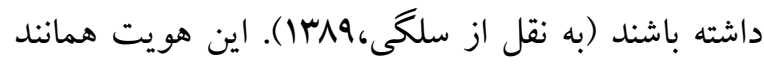
ساير انواع هويت مركب، جِند گانه، آميخته و نسبى بوده و ييوسته در حال بازسازى و تحول است و همراه با تغيير نيازهاى بيولوزيكى و روانشناختى و همجنين تغيير شرايط

6- DAN P, McADAMS and KEITH S. COX

7- Topolewska-Siedzik E \& Cieciuch J

- Identity

2- Wetherell M

3 - Olson ET

4- Schlenker BR

5 - Marcia JE 
توسط آدامز و همكاران (1999) تهيه شده است؛ اما نكتهاى كه در اين رابطه قابل توجه است اين است كه هويت شخصى هر كس به شدت تحت تاثير محيط و

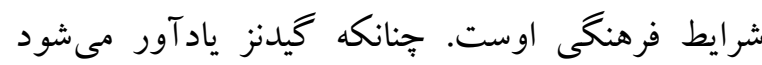
محتواى هويت شخصى مانند ديخر عرصههاى وجودى، از نظر اجتماعى و فرهنگى متغير است. براى مثال نام شخص، نخستين عنصر زندگينامه اوست. آداب و رسوم، نام كذارى اجتماعى، اينكه نام افراد تا جهه حد معرف له روابط خونى و خويشاوندى آنها است، همه بر حسب آن

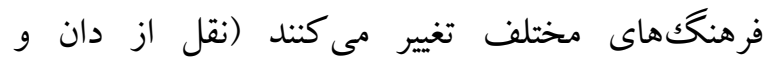

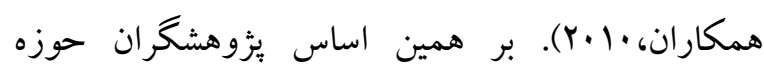
هويت معتقدند كه ابزارهاى سنجش هويت حتما بايد مولفه هاى اختصاصى هر فرهنگ روا كاوش كنند و در فرهنگ محل سنجش مشخصه هاى روانسنجى آنها مورد

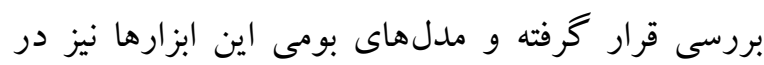
صورت امكان طراحى شوند. از آنجا كه تا كنون فرم كوتاه اين ابزار در جامعه ايرانى طراحى و هنجاريابى صورى نشده است؛ محققان اين بثوهش مناسب ديدند به جاى ساخت ابزار جديد، ضمن اجراى يرسشنامه آدامز، ايرادات احتمالى آن را شناسايى كرده و در صورت امكان سوالات نامطلوب، غير قابل فهم و غير مرتبط با فرهنگ اير انى آن را اصلاح نمايند و علاوه بر ارائه نسخه كوتاه شده اين فرم مشخصههاى روانسنجى آن را در جامعه ايرانى مورد بررسى قرار دهند.

\section{روش} يثزوهش حاضر از نظر هدف كاربردى است. از حيث نوع كردآورى اطلاعات بيمايشى و از نظر روش شناسى، از جمله مطالعات آزمون سازى به حساب مى آيد كه در
زندگى فر آيند هويت فردى نيز تحت تاثير قرار مى گيرد

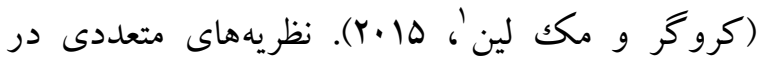
خصوص سنجش هويت فردى مطرح شدهاند اما از ميان اين نظريات جارجوب مفهومى يُوهش حاضر بيشتر بر اساس نظريات و مدلهايى خواهد بود كه در جهت عينى سازى و سنجش اين مفهوم موفقيتهاى قابل توجهى داشتهاند كه از ميان آنها مىتوان به مدل مارسيا بر مبناى نظريه اريكسون و در نهايت ابزار استاندارد شده آدامز و همكاران اشاره كرد. مارسيا (1999) با الهام از نظريه اريكسون جهار نوع هويت طرح كرد كه لزوماً مراحل متوالى يك زنجيره رشدى نيستند ولى در عين حال ماهيت ثابتى نداشته و ممكن است بتدريج دگرگون

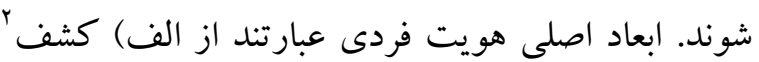

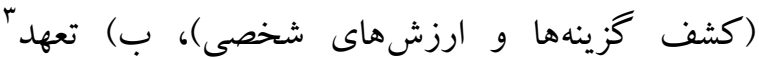
(سرمايه كذارى شخصى جهت رسيدن به هويت مورد نظر) مارسيا بر اساس فرايند كاوشخرى و تعهد، جهار بايگاه را براى هويت مشخص نموده است كه هر يكك؛ ميزان كاوشگرى و تعهد را نشان مىدهد. اين جهار منزلت (يايگاه) هويتى عبارتند از: هويت موفق (هويت

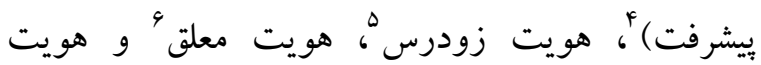

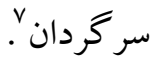
امتيازى كه مدل مارسيا در مقايسه با ساير نظريههاى ارائه شده دارد، مشخص كردن سطوح قوت (امن") و نيز امكان تمايز منزلت هويتى بهنجار از نابهنجار است (رحيمىنزاد،

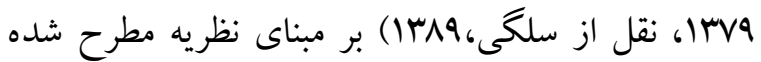
توسط مارسيا و همكاران مناسبترين ابزار براى اين مقصود

\footnotetext{
1 - Kroger J, McLean KC

2 - Exploration

3 - Commitment

4 - Identiy achived

5 - Identity foreclosure

6- Moratorium

7- Identity diffusion
} 
9 سوال براى هر يايگاه هويتى شامل YF سوال براى برسشنامه سنجش عينى هويت بود (آدامز و همكاران،

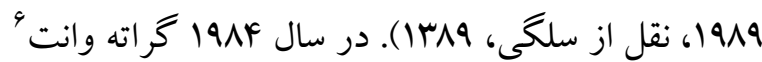

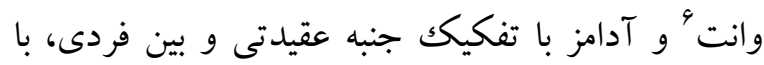
توسعه برسشنامه سنجش عينى بايگًاه هويت من، اولين

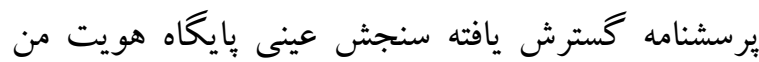
را ساختند. اين يرسشنامه در بخش (EOM-EIS-1) عقيدتى، جهار محتواى شغل، سياست، فلسفه زندگى و مذهب را (با در نظر كرفتن r سوال براى هر يك از جهار محتوا و جمعاً ^ موال براى هر بايكاه هويتى) شامل

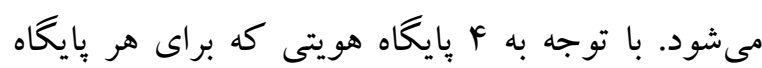

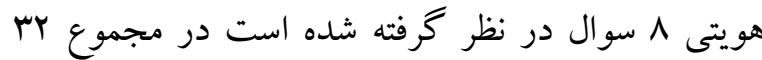
سوال به بخش عقيدتى هويت اختصاص يافته است. در بخش هويت بين فردى نيز جهار حيطه نقش جنسى، انتخاب دوست، تفريح و وعده ملاقات با جنس مخالف در نظر كرفته شده است. تعداد سوالات اين بخش نيز مانند بخش عقيدتى بr سوال و در كل، برسشنامه داراى

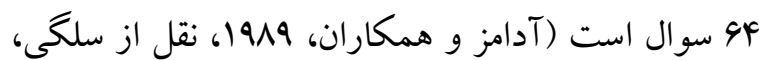

.$(1) \wedge 9$ در سال 1919 آدامز و بنيون ل با اصلاح برسشنامه خصوصاً در بخش بين فردى، دومين (EOM-EIS-1) برسشنامه كسترش يافته سنجش عينى بايگاه هويت من AF را با حفظ همان ساختار و با همان (EOM-EIS-2) سوال مورد اصلاح قرار دادند (آدامز و همكاران، 1919،

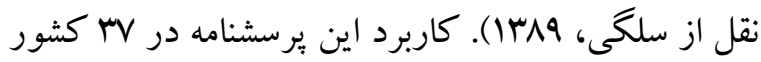
گزارش شده است. آدامز و همكاران، اعتبار و بايايى يرسشنامه را در حد قابل قبولى گزارش كردهاند. در مطالعه پِايايى بِرسشنامه، ضريب آلفاى كرونباخ (اجرا

6 - Gratevant

${ }^{7}$ - Bennion
قالب كلى يك طرح يثزوهشى توصيفى انجام گرفته است.

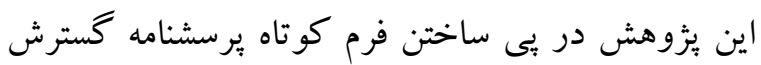
يافته سنجش عينى هويت من و همجنين سنجش مشخصه هاى روانسنجى آن در جامعه ايرانى است. نظر به وجود بِارهاى ايرادات در سوالات برسشنامه مورد اشاره، اين بثزوشش درصدد بوده است ضمن حذف سوالات نامناسب، فرم كوتاهتر (كه قابليت استفاده بهتر و سريعتر را دارد) تهيه نمايد. جامعه آمارى اين بثوهش شامل كليه دانشجويان دانشگاههاى سراسرى (دولتى) تهران مىباشد. با روش نمونه كيرى تصادفى خوشهاى، يك نمونه .. نفرى از دانشگاهها انتخاب و برسشنامه روى آنها اجرا و و در نهايت هY هY يرسشنامه جمع آورى گرديد. در مراحل اجراى بُزوهش معيارهاى اخلاق يُوهش از جمله اخذ رضايت آكاهانه شركت كنند كان و محرمانكى اطلاعات آنها رعايت شد. همجينين به منظور ارزيابى اين مقياس، روش به كار كرفته شد: تحليل گُويهها، باياسازى،

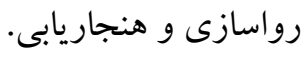

\section{ابزار} برسشنامه هويت فردى آد/مز' (EMO-EIS-2): اين يرسشنامه داراى FF كويه مىباشد كه بر مبناى درجهبندى

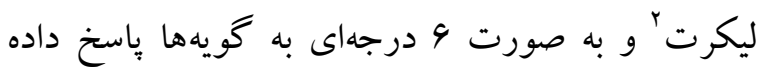
مى شود. برسشنامه سنجش عينى هويت من در سال $19 V 9$

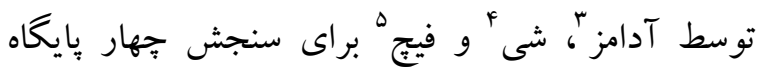
هويتى سردر گم، زودرس، معوق و موفق در سه حيطه شغل، سياست و مذهب ساخته شد. تعداد سوالات اين برسشنامه با توجه به طراحى ب سوال در هر حيطه و جمعاً

\footnotetext{
1- Extended objective measure of ego identity states

2- Likert,s Scale

3 - Adams

4- Shea

5 - Fitch
} 
براى تحليل گويهها از دو روش ضريب تميز و روش

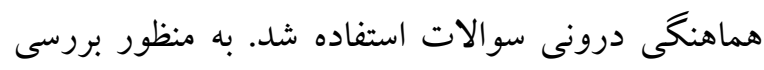
ضريب تميز لازم است ميزان همبستكى هر كويه با نمره كل آزمون بدست آيد. در بررسى ضريب تميز سوالات

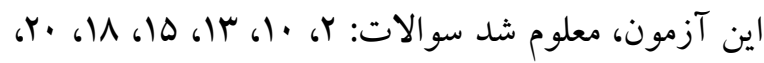

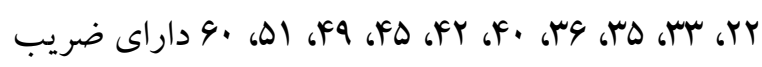
تميز منفى و يا ضريب تميز تصادفى مىباشند. همجينين در روش هماهنكى درونى سوالات، ضريب يايايى كل

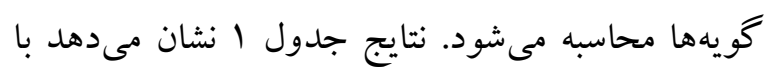

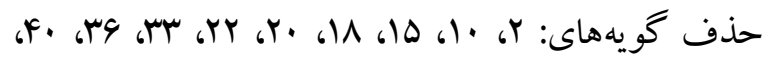

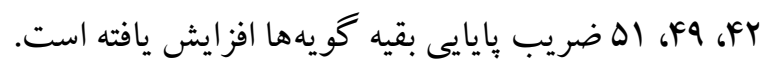

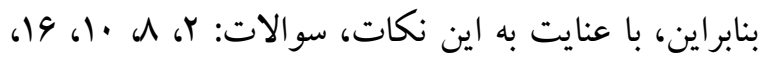

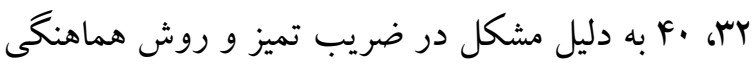
درونى سوالات حذف شدند. نتايج تحليل كويهها در

$$
\text { جدول ا آمده است. }
$$

شده روى N

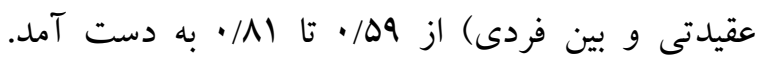
ضريب بايايى آزمون- آزمون مجدد محاسبه شده از

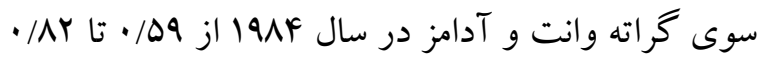
كزارش شده است. در مطالعه بنيون و آدامز (1919) ضريب آلفاى مقياسهاى بين فردى هـ/ • بود؛ در حالى

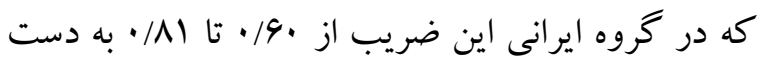

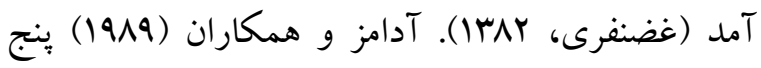
نوع اعتبار را در مورد برسشنامه (EOM-EIS-1) و مورد بررسى قرار دادهاند كه عبارتند از (EOM-EIS-2) ييشبين، همزمان و دو نوع اعتبار سازه شامل: اعتبار تحليل عاملى، همخر او واگر ا.

يافته ها تحليل كويهها

\begin{tabular}{|c|c|c|c|c|c|}
\hline 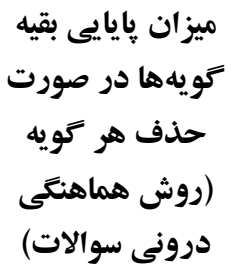 & ضريب همبستكى كويه با جمع & شماره & 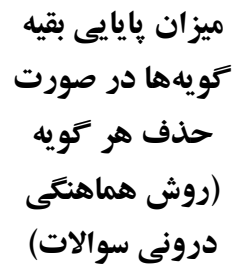 & 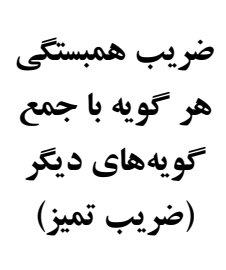 & شماره \\
\hline$\cdot|\wedge 9|$ &.$/ 1 Y q$ & r & ./АQ. & - / TFF & 1 \\
\hline - $1 M M 9$ & ז & $r \varepsilon$ & - /A9Y & $\cdot / V Y$ & $r$ \\
\hline ./Aq. & $\cdot / \mid \mathrm{VI}$ & ro & - IMV & - / pat & $r$ \\
\hline$\cdot|\wedge 9|$ &.$/ 11$ & ry & $\cdot / M M$ & ו & $\varepsilon$ \\
\hline - IMAS & - IDSV & rV & $\cdot / 1 M 9$ & $\cdot / Y \wedge q$ & 0 \\
\hline - /MAS & . 19YD & rᄉ & $\cdot / 1 M 9$ & • & 7 \\
\hline$\cdot / M V V$ & . $/ \Delta r$. & rq & - /Aq. &.$/ 19 \mathrm{~V}$ & $\checkmark$ \\
\hline - / $1 \wedge 9 \mid$ & $\cdot / 101$ & $\varepsilon$. & - $/ M \wedge 9$ & $\cdot /$ T49 & $\wedge$ \\
\hline - $/ M A 9$ & $\cdot 19 \cdot \Delta$ & \&l & - $1 M M 9$ & $\cdot / T V V$ & 9 \\
\hline - / $149 r$ &.$/ \cdot 1$ & $\varepsilon r$ & $\cdot \mid \wedge 91$ &.$/ I F V$ & 1. \\
\hline ./1८9. & - MFG & $\varepsilon r$ & $\cdot / \wedge q$ & • MYYY & 11 \\
\hline - IMAS & $\cdot \mid 091$ & $\varepsilon \varepsilon$ & - $11 M 9$ & •/rYV & ir \\
\hline
\end{tabular}




\begin{tabular}{|c|c|c|c|c|c|}
\hline 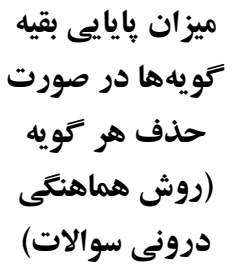 & ضريب همبستگى كويه با جمع & شماره & 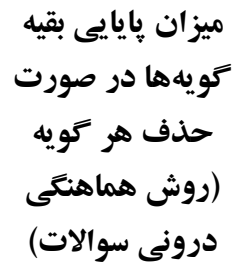 & ضر ضويب همبستغى نويه با جمع & شوماره \\
\hline ./Aq. &.$/ 19$ & $\varepsilon 0$ & - /А & - MgF & ir \\
\hline - /MA & - IYFA & $\varepsilon\rceil$ & ./АQ. & - /TDF & $1 \varepsilon$ \\
\hline$\cdot / M A$ & . & $\varepsilon Y$ & $\cdot|\wedge 9|$ & $\cdot / 1 \cdot r$ & 10 \\
\hline$\cdot / M A$ & $\cdot / M V I$ & $\varepsilon \wedge$ & ./Аq. & . IYYY & 17 \\
\hline$\cdot / 1991$ & $\cdot / 1$ & $\varepsilon q$ & $\cdot / \mathrm{MAV}$ & - /DYV & IV \\
\hline - /MV &.$/ 490$ & 0. & - / $A 94$ & $-\cdot / \cdot r$ & 11 \\
\hline$\cdot|199|$ & هr/. & 01 & - $14 M 9$ & $\cdot / Y M$ & 19 \\
\hline$\cdot / M A$ & $\cdot / M V$ & or & $\cdot / 199$ & - / IDr & $r$. \\
\hline$\cdot / M A$ & - IFYD & or & $\cdot / M M$ & ./ & $r 1$ \\
\hline - /MV & $\cdot / 4 \mathrm{VI}$ & or & - /1991 & תr/I & rr \\
\hline . /199. & $\cdot / r \cdot 1$ & 00 & $\cdot / M M$ & $\cdot / 4 \cdot \Lambda$ & rr \\
\hline . $1 \mathrm{M} 9$ & $\cdot / r V I$ & or & $\cdot / \mathrm{MVV}$ & - /afat & $r \varepsilon$ \\
\hline$\cdot / M \Lambda$ & • / & or & $\cdot / M A V$ &.$/ 01$ & ro \\
\hline$\cdot / M V V$ & - / FVa & 01 & - IMM & - Maf & $r$ \\
\hline$\cdot / M M$ & $\cdot / F \cdot f$ & 09 & - IMAS & - /DVq & rr \\
\hline ./Aq. &.$/ M A F$ & 7. & $\cdot / \mathrm{AVV}$ &.$/ 01$ & $r \wedge$ \\
\hline$\cdot / M \Lambda$ & •/Nו & 71 & $\cdot / \mathrm{MAV}$ & . Ifrg & $r q$ \\
\hline . IMAS & . & tr & - $11 M 9$ & . Mgr & $r$. \\
\hline - IMAS & | & ז' & . /1 9 . & - MFF & r \\
\hline - IMA &.$/ 0 Q$. & $7 \varepsilon$ & ./Аq. & $\cdot / r \cdot \Delta$ & rr \\
\hline
\end{tabular}

شده است و با عنايت به حذف 9 سوال در مطالعات

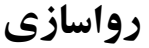
تحليل گويه (به دليل نافهم بودن اين 4 سوال، براى به منظور رواسازى ״رسشنامه حاضر، از روايىسازه' باسخكوى ايرانى)، برسشنامه حاضر همان برسشنامه آدامز استفاده شد. براى مشخص كردن اين مطلب كه مجموعه نخواهد بود، لذا به جاى تحليل عامل تاييدى، از تحليل مواد تشكيل دهنده برسشنامه از جند عامل مهم و معنادار

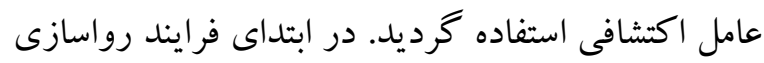
اشباع شده است، تحليل عامل اكتشافى 'از طريق تحليل و با هدف تعيين كفايت نمونه منتخب جهت اجراى

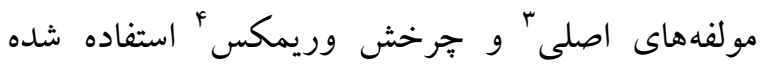
يروسه تحليل عاملى، از آزمون كفايت نمونه بردارى است. نظر به اينكه يرسشنامه آدامز از بو سوال تشكيل

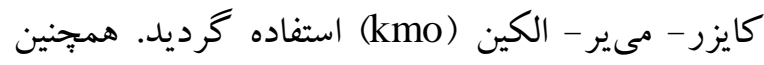
براى اينكه مشخص شود همبستگى بين مواد آزمون در

\footnotetext{
1. Construct Validity

${ }^{2}$ - Exploratory factor analysis

3 - Principal component

4 - Varimax rotation
} 
است. اين نشان دهنده آن است كه مىتوان از تحليل عامل اكتشافى استفاده كرد. اطلاعات مربوط به تحليل عامل در جداول r و r آمده است.
جامعه، برابر صفر نيست از آزمون كرويت بارتلت استفاده

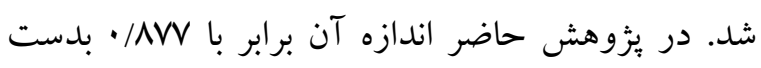
آمده است كه ميزان قابل قبولى است. همجينين آزمون كرويت بارتلت در سطح معنادارى P< Pعندادار

جدول r مجموع واريانس تبيين شده

\begin{tabular}{|c|c|c|c|c|c|c|}
\hline \multirow{2}{*}{ عوامل } & \multicolumn{3}{|c|}{ مجموع مجذورات انتقال يافته قبل از جرخش } & \multicolumn{3}{|c|}{ مجموع مجذورات انتقال يافته بعد از جرخش } \\
\hline & جمع كل & درصد واريانس & درصد تراكمى & جمع كل & درصد واريانس & درصد تراكمى \\
\hline 1 & $1 \cdot / 494$ & IV/AVR & IV/AVT & V/AGV & $\mid r / \Delta G F$ & $\mid r / \Delta G F$ \\
\hline r & $9 / 490$ & $11 / 1 F V$ & $r q / \cdot r$ & $r / 991$ & $9 /$ MGF & $19 / 9 Y \wedge$ \\
\hline$r$ & $r / \mu$ & $\Delta / 9 \wedge 9$ & $M F / V \cdot q$ & $r / .90$ & D/M & TD/YGA \\
\hline f & r/OMF & $f /$ raq & $\mathrm{rq} / \cdot \mathrm{VA}$ & $r / . q F$ & ه & $r \cdot / 099$ \\
\hline$\Delta$ & $r / T r \Delta$ & $r / 994$ & FY/VAT & $r / 91 r$ & $\Delta / \cdot Y r$ & $r \Delta / 9 Y I$ \\
\hline 4 & I/VAF & $r / \cdot V q$ & $F D / A / q$ & r/VID & $F / 911$ & $r \cdot / r \cdot r$ \\
\hline V & I/DFY & $r / 909$ & FA/FVA & $r / \mu \cdot r$ & $r / 99 \Lambda$ & $F F / Y V$ \\
\hline$\wedge$ & 1/Mr & $r / Y Q V$ & $\Delta \cdot / V V F$ & Y/IFA & $r / v \cdot r$ & $F V / 9 V T$ \\
\hline 9 & $1 / Y V q$ & $r / Y \cdot \Delta$ & $\Delta r / 9 \Lambda$ & $Y / \cdot \Delta G$ & $\Gamma / D F D$ & $\Delta 1 / 011$ \\
\hline 1. & $|/ r|$ & $\mathrm{r} / \cdot \wedge \varphi$ & $\Delta \Delta / \cdot 9 \Delta$ & $1 / 499$ & r/DrT & $\Delta F / \cdot \Delta r$ \\
\hline 11 & I/ITr & $1 / 901$ & $\Delta V / \cdot 19$ & $1 / F F q$ & $r / 4 q \Lambda$ & $\Delta 9 / \Delta \Delta$ \\
\hline Ir & $1 / \cdot v^{r}$ & $1 / A \Delta 1$ & $\triangle \Lambda / \wedge G V$ & $1 /$ KFF & r/TIV & $\triangle \Lambda / \wedge Q V$ \\
\hline
\end{tabular}

جدول ץ بارهاى عاملى ير سشنامه هويت فردى يس از جرخش

\begin{tabular}{|c|c|c|c|c|c|c|c|c|}
\hline عامل 1 & عامل V & عامل 7 & عامل 0 & عامل ع & عامل r & عامل r & عامل 1 & شماره كويه \\
\hline & & & & & & & . /VVG & $r r$ \\
\hline & & & & & & & $\cdot / \mathrm{\Delta A}$ & $r q$ \\
\hline & & & & & & & . NQT & rᄉ \\
\hline & & & & & & & DNYY & $7 \varepsilon$ \\
\hline & & & & & & & . Nr. & rY \\
\hline & & & & & & &.$/ 219$ & זד \\
\hline & & & & & & & $.199 \mathrm{~V}$ & $\varepsilon \varepsilon$ \\
\hline & & & & & & & .1994 & $7 r$ \\
\hline & & & & & & & .1944 & $r$ \\
\hline & & & & & & & .194. & $r \Lambda$ \\
\hline & & & & & & & $.19 \pi$ & $r \varepsilon$ \\
\hline & & & & & & &.$/ 9 \mathrm{YV}$ & $\varepsilon 1$ \\
\hline & & & & & & & .1914 & ri \\
\hline
\end{tabular}




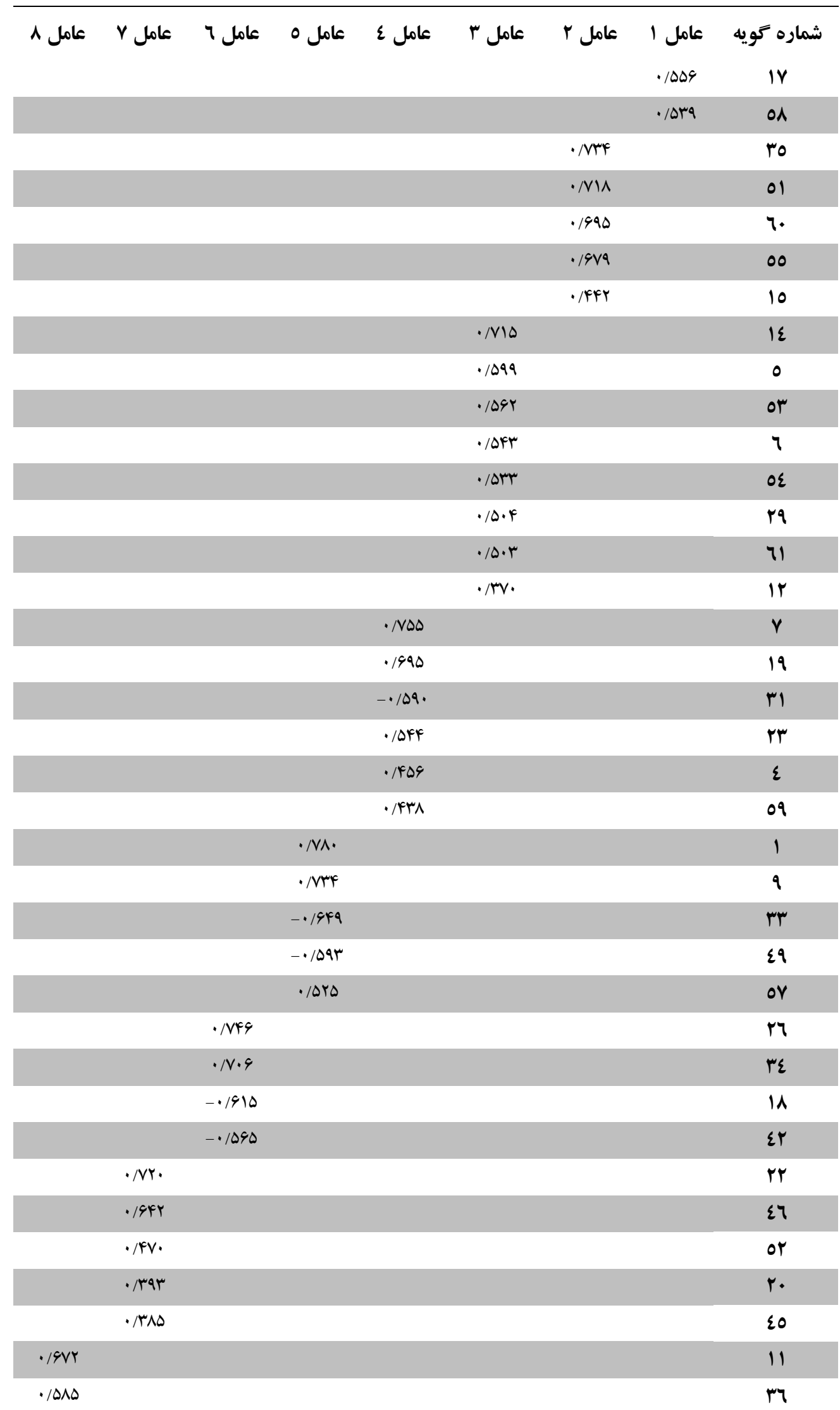

مجله روانشناسى و روان بزشكى شناخت، سال هفتم، شماره 9، 99 1، 101-14 


\begin{tabular}{|c|c|c|c|c|c|c|c|c|}
\hline عامل 1 & عامل V & عامل 7 & عامل 0 & عامل ع & عامل r & عامل r & عامل 1 & شماره كويه \\
\hline$\cdot / 4 \wedge q$ & & & & & & & & $\varepsilon r$ \\
\hline 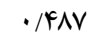 & & & & & & & & $\varepsilon \wedge$ \\
\hline
\end{tabular}

جدول ع ضريب هايايى هايكاههاى هويت و ضريب هايايى كل

\begin{tabular}{|c|c|}
\hline \multicolumn{2}{|c|}{ يرسشنامه } \\
\hline ضريب آلفا & يا يَكاهها \\
\hline.$/ 91 F$ & زودرس \\
\hline$\cdot / \mathrm{Nr}$ & موفق \\
\hline - NGA & معوق \\
\hline - NVED & سردر \\
\hline - IMG & كل آزمون \\
\hline
\end{tabular}

با توجه به اطلاعات مندرج در جدول فوق مىتوان كفت

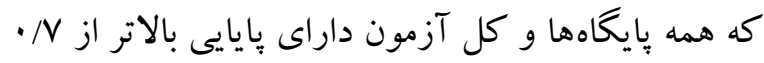
مىباشد كه نشان دهنده مناسب بودن ميزان بايايى است.

\section{هنجاريابى}

به منظور هنجاريابى آزمون هويت فردى از روش رو إبى

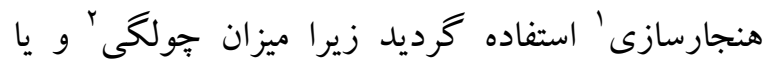
كشيدگى “ّ خارج از حد مجاز بود.

جدول ه جدول هنجاريابى برسشنامه

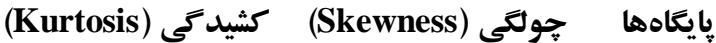

\begin{tabular}{|c|c|c|}
\hline$\cdot / \mu \cdot \Lambda$ & $* \cdot 1911$ & زودرس \\
\hline$\cdot / Y M$ & - & موفق \\
\hline.$/ Y G V$ & - /YA9 & معوق \\
\hline$* \cdot$ Var & $* \cdot / \wedge \Delta \wedge$ & سردرگم \\
\hline
\end{tabular}

بر اين اساس تعداد سوالات از \& و سوال به به سوال تقليل يافت كه به شرح زير در عوامل هشتگانه حاصله توزيع

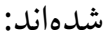

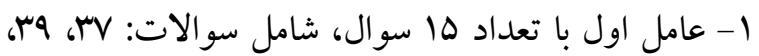

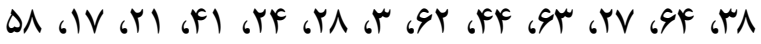
(همخو ان با بايگاه هويت زودرس) ץ- عامل دوم با تعداد ه سوال، شامل سوالات: ها، اله، 9، هذه، ها (همخوان با بايگاه هويت موفق)

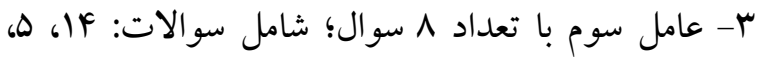
rه، 9

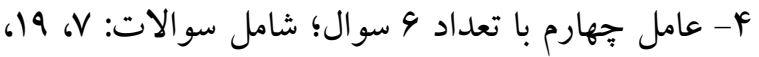

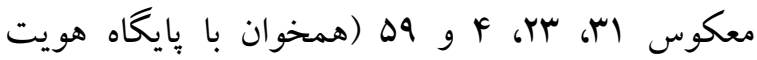

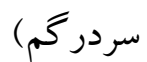
ه- عامل هفتم با تعداد ه سوال، شامل سوالات: YY TY، FG، ه

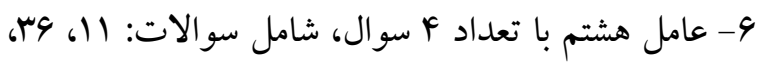

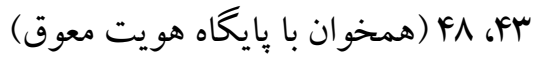

\footnotetext{
:إيايى پايايى اين برسشنامه از طريق آلفاى كرونباخ ابتدا براى

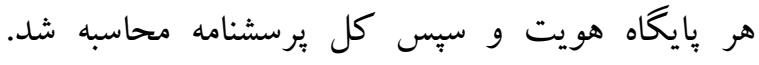

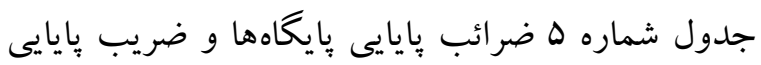
كل برسشنامه را نشان مىدهد.
}

- Normalization

2 - Skewness

${ }^{3}$ - Kurtosis 
مىشود. بنابراين عوامل ينجم و ششم در هويت فردى

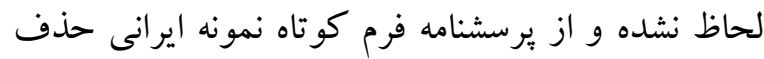
كرديدهاند.

- عامل هفتم با عنوان (اتوانايى انتخاب و رضايت از زندگى") با بايگاه هويت موفق همخوان است. نهايتاً عامل هشتم با عنوان (جستجو و كاوشگرى)" با بايگاه هويت معوق همخوان است. با توجه به اين اطلاعات،

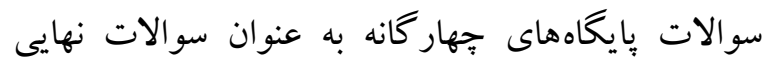
انتخاب شدهاند. و نهايتاً اينكه فرم كوتاه ايرانى برسشنامه

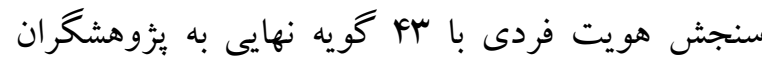

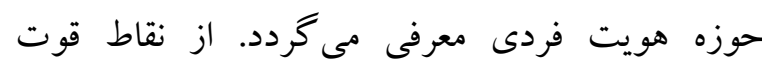
يُزوهش حاضر مىتوان به اين نكته اشاره كرد كه دانشگاههاى دولتى شهر تهران تنوعى از دانشجويان اقوام

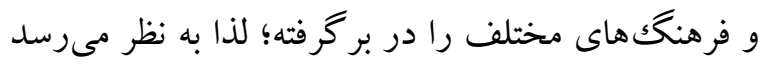

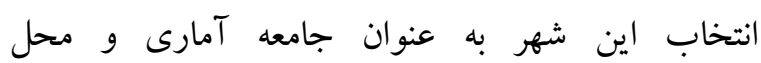
نمونه گيرى بازنمايى مناسبى از مقتضيات جامعه ايرانى و و ولهو

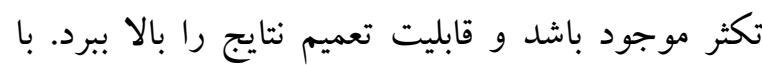
عنايت به اينكه هويت فردى در WV كشور تر جمه و به كار كرفته شده است، خلاء آزمونى در اين حيطه سنجشى در كشور احساس مى شد و حال كه نسخه كوتاه فارسى اين آزمون از ويز گیىهاى روانسنجى مناسبى برخوردار است،

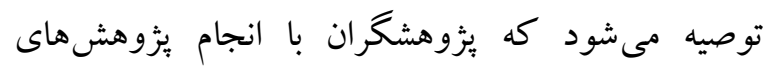
كستردهتر خلاء بيزوهشى موجود در اين حيطه را نيز

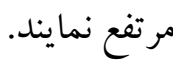

\section{نتيجه كيرى}

در مجموع مىتوان نتيجه گرفت كه اين يرسشنامه در فرهنگك ايرانى از بايايى و روايى مناسبى برخوردار است و عوامل بدست آمده از تحليل عامل مىتواند بايڤاه
هدف از مطالعه حاضر ساخت، ياياسازى، رواسازى و هنجاريابى يرسشنامه هويت فردى، (فرم كوتاه) براى استفاده در ايران بود. به منظور پاياسازى و رواسازى اين مقياس از روش هاى مختلفى استفاده شد. ابتدا همه كويههاى فرم بلند تحليل شدند و ضريب تميز و روش لو ب براى هر گويه در فرم بلند محاسبه شد كه گويههاى بهري

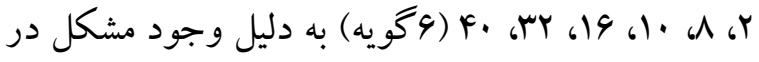
ضريب تميز و روش لوٍ حذف شدند. بقيه گويهها مناسب بودند كه در محاسبات بعدى استفاده شدند. در رواسازى، از روشهاى روايى سازه استفاده شد. در روايى سازه، روش تحليل عامل اكتشافى مورد استفاده قرار گرفت. با توجه به نتايج تحليل عامل، 1 عامل شناسايى گرديد كه 9 عامل آن با مفاهيم پيايخاههاى هويتى مطابقت داشتند كه عبارتند از: - عامل اول به طور كامل با پايڤاه هويتى زودرس منطبق بود. - عامل دوم با عنوان (توانايى انتخاب و مسئوليتيذيرى") و عامل هفتم با عنوان (اتوانايى انتخاب و رضايت از زندكى")، جمعاً با بايخاه موفق همخو ان هوان است. - عامل سوم با عنوان (اتحول توانايى انتخاب) به همراه

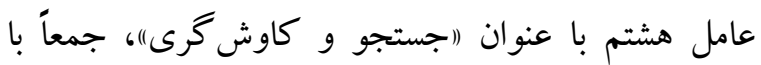
يايگاه معوق همخوان است.

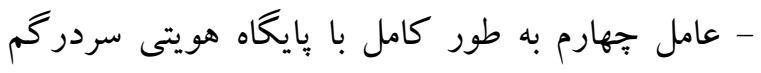

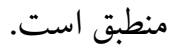
- عامل ينجم با عنوان (عدم توانايى در انتخاب شغل" و عامل ششم با عنوان (عدم توانايى در انتخاب دين" متمركز بر مشتركات يا عدم تفاوت مىباشند. اين در حالى است كه در فرايند هويت فردى بر تفاوتها تاكيد 
(Eds.), Handbook of identity theory and research (pp. 99-115). New York: Springer.

Olson ET. (2002). Personal Identity, in: The Stanford Encyclopedia of Philosoghy, Edward N.Zalta (ed.) available at: http://plato Stanford. edu /entries/identity-personal.

Schlenker BR. (2012). Self-presentation. In M. R. Leary \& J. P. Tangney (Eds.), Handbook of self and identity (2nd ed., pp. 542- 570). New York: Guilford.

Solgi M. (2011). Investigating the Dimensions and Components of Individual and Social Identity and those Influencing the National Identity among Tehran University Student with Structural Equation Modeling. (In Persian)

Topolewska-Siedzik E, Cieciuch J. (2018). Trajectories of Identity Formation Modes and Their Personality Context in Adolescence. Journal of youth and adolescence, 47(4), 775-792.

Vignoles V. (2017). Identity: Personal AND Social. Oxford Handbook of Personality and Social Psychology (2nd ed.)

Wetherell M. (2010). The field of identity studies. In M. Wetherell \& C. T. Mohanty (Eds.), The Sage handbook of identities (pp. 3- 26). London, England: Sage.

$$
\begin{aligned}
& \text { هويتى آزمودنى را به گونهاى مناسب اندازه گيرى كند و } \\
& \text { نسخه كوتاه بيشنهادى توسط اين بثزوهش مى تواند مبناى } \\
& \text { كار بزوهشخران داخلى در حوزه هويت فردى قرار گيرد. }
\end{aligned}
$$

$$
\begin{aligned}
& \text { سياسگز ارى } \\
& \text { نويسندهًان مطالعه حاضر مراتب سياس و قدردانى را از } \\
& \text { تمامى آزمودنىهايى كه در تكميل برسشنامه ها همكارى } \\
& \text { لازم را داشتند به عمل مى آورند. لازم به ذكر است كه } \\
& \text { اين يثزوهش بركرفته از رساله دكترى نويسنده مسئول } \\
& \text { مىباشد كه به شماره كد تصويب يايان نامه IIIF/AV } \\
& \text { در دانشگاه علامه طباطبائى تهران ارائه شده است. } \\
& \text { همجينين تمامى معيارهاى رعايت اخلاق در يُزوهش كه } \\
& \text { در هيزوهش حاضر موضوعيت داشت همسو با بيانيه } \\
& \text { هلسينكى رعايت شده است. }
\end{aligned}
$$

\section{References}

Adams GR. (1998). The objective measure of ego identity status: A reference manual.

Bennion L, Adams GR. (1986). A revision of the extended version of the objective measure of ego identity status instrument for use with late adolescents. Joumal of Adolescent Research, 1, 183-198.

Dan P, Mc A, Ketth Cox S. (2010). Self and Identity across the Life Span. The Handbook of LifeSpan Development, edited by Richard $\mathrm{M}$. Lemer, Michael E. Lamb, and Alexandra M. Freund John Wiley \& Sons, Inc. 158.

Kroger J, McLean KC. (2015). The Oxford handbook of identity development. Oxford, United Kingdom: Oxford University Press;. Identity development through adulthood: The move toward "wholeness." M. Syed(Eds.)

Marcia JE. (1966). Identity in adolescence. Handbook of Adolescent Psychology. 9:159-187.

McAdams DP. (2011). Narrative identity. In S. J. Schwartz, K. Luyckx, \& V. L. Vignoles 